\title{
South African Sign Language and language-in-education policy in South Africa
}

\author{
Timothy Reagan \\ University of the Witwatersrand and \\ Central Connecticut State University, Connecticut, 06032, USA \\ reagantig@ccsu.edu
}

\section{Introduction}

Language planning and language policy issues and decisions are both significant and often controversial in the educational sphere. In the case of South Africa, language planning and language policy have a long and complex history in South Africa. Used in the apartheid era both to support Afrikaner nationalist objectives and as a pillar of ethnolinguistically separate education, language planning and policy have remained an important and divisive matter well into the new democratic era (cf. Heugh 1995, 2002; E. de Kadt 1996; Ridge 1996, 2004; Chisanga and Kamwangamalu 1997; Kamwangamalu 1997, 2004; Verhoef 1998; Reagan 2001, 2002a; Alexander 2004; J. de Kadt 2006). As Heugh (2002) commented not quite a decade after the establishment of democracy,

(1)anguage policy developments in South Africa have undergone dramatic changes over the last decade. Explicit statements of policy have shifted away from the segregationist mould of the previous apartheid government with the widely divergent roles and functions it ascribed to the various languages of the country. There is now a move toward principles that espouse the equal promotion of respect for, and use of, other languages. The extraordinary 
circumstances surrounding the political negotiations that led to a sharing of power after the country's first democratic elections of 1994 created the opportunity for 'proposals from below' (from civil society), to take root in a manner which has never before been possible in South Africa. Many of the proposals for new language policy have been accepted on an official level and an encouraging, optimistic environment seemed, in the early years of the new government of national unity, to promise a vibrant future for language development and multilingualism.

Heugh (2002: 449)

As this passage suggests, there is extensive and growing literature, both in applied linguistics and in education, that addresses issues related to most aspects of language-in-education policy in contemporary South Africa. ${ }^{1}$ One area in which the literature remains fairly sparse, however, has been that of the implications of current government policy for South African Sign Language (SASL) (cf. Reagan, Penn and Ogilvy 2006; Reagan 2007a). The goal of this article is to present an overview of the complex issues presented by the case of SASL for language-in-education policy, and to offer a series of recommendations for how these issues might best be addressed.

\section{Understanding 'deafness'}

\subsection{Competing paradigms of deafness}

This paper deals with a number of complex cultural and linguistic issues with respect to deafness and the deaf cultural community (in American Sign Language (ASL), this concept is expressed in the sign DEAF-WORLD ${ }^{2}$ ) (cf. Bragg 2001). ${ }^{3}$ Therefore, it is appropriate to briefly identify some of the conceptual and terminological issues that will be explored here. First, it is important to understand that there is a common distinction made in writing about deafness between "deaf" and "Deaf": the former refers to deafness solely as an audiological condition, the latter to Deafness as a cultural condition. The basic idea underlying this distinction is that when writing about cultural groups in general, upper case letters are employed (e.g., African American). Thus, a person can be deaf without being Deaf (as in the case of an older person who gradually loses his/her hearing). This commonly accepted practice has been followed here, although one might raise the concern that it has the potential to oversimplify and 
dichotomise the complexity of membership in the Deaf community. In fact, deafness is not only socially and individually constructed, but its construction is complex and multilayered (cf. Lane, Hoffmeister and Bahan 1996; Branson and Miller 2002; Reagan 2002b, 2005a; Ladd 2003; Padden and Humphries 2005).

The division between the two major ways of viewing deafness is actually paradigmatic in nature, going far beyond mere competing models or theories (cf. Kuhn 1996). This paradigmatic boundary is between those who see deafness as an audiological matter, and thus view it as an essentially medical condition subject to medical interventions, and those who view it rather as a social, cultural and linguistic condition which merely happens to overlap particular medical issues. The former paradigm for understanding deafness is commonly called the "pathological" or "medical" paradigm, while the latter is known as the "sociocultural" paradigm. These two paradigms lead to radically different approaches to responding to deafness and the deaf. While the pathological or medical paradigm, which emphasises deafness as a disability, is arguably the dominant paradigm in both hearing society and in much of deaf education, the sociocultural paradigm has been gaining increasing attention and support in recent years. As Edward Dolnick noted in an essay published in The Atlantic in 1993,

(1)ately ... the deaf community has begun to speak for itself. To the surprise and bewilderment of outsiders, its message is utterly contrary to the wisdom of centuries: Deaf people, far from groaning under a heavy yoke, are not handicapped at all. Deafness is not a disability. Instead, many deaf people now proclaim, they are a subculture like any other. They are simply a linguistic minority (speaking American Sign Language) and are no more in need of a cure than are Haitians or Hispanics.

(Dolnick 1993: 37)

With this in mind, we turn now to a brief overview of this way of understanding deafness and the culture of the DEAF-WORLD, especially with respect to its implications for education and language policy. 


\subsection{Deafness and the DEAF-WORLD}

In discussions about the complex relationships that can and do exist between language and identity, Deaf people stand out as an exceptionally complicated and intriguing case (cf. Reagan 1995, 2002c). As Baker (1999: 129) observed, "Deaf people do not necessarily identify with the hearing world and increasingly regard the hearing world as a different language community. Rather than allowing themselves to be defined by the majority hearing group, Deaf people are progressively expressing and valuing their own self-constructed identity." Since the 1970s, there has been a growing recognition that many individuals identify themselves as members of a common Deaf cultural community. Such a cultural conceptualisation of deafness presents a significant challenge to the more popular view amongst hearing people of deafness as a disability. The difference is not merely a semantic one; it is fundamental to one's conception of what deafness is, what it means to be deaf, and how both individuals and society as a whole ought to address deafness. As Lane et al. (1996: 371) have noted, "when hearing people think about Deaf people, they project their concerns and subtractive perspective onto Deaf people. The result is an inevitable collision with the values of the DEAF-WORLD, whose goal is to promote the unique heritage of Deaf language and culture. The disparity in decision-making power between the hearing world and the DEAFWORLD renders this collision frightening for Deaf people." Furthermore,

(t)he complexities of the situation become even greater when one takes into account the fact that not all deaf people are Deaf. Audiological deafness and cultural Deafness are distinct and different conditions. The deaf population can be subdivided into a wide range of different groups, distinguished in part by degree of hearing loss, but also by language preference, educational experience, and relative integration into either the DEAF-WORLD or the hearing world.

(Hagemeyer 1992)

The single most significant element of Deaf cultural identity in the United States (and, by extension, in South Africa) is communicative competence in the natural sign language of the Deaf community (ASL in the United States, SASL in South Africa) (cf. Schein and Stewart 1995; Lane et al. 1996; Valli, Lucas and Mulrooney 2005). Sign language serves multiple roles within the Deaf community, functioning not only as the community's vernacular 
language, but also as an indicator of cultural group membership. Sign language plays an important role in the construction of what could be termed the DEAF-WORLD worldview - that is, the way in which Deaf people make sense of the world around them. It does this in two distinct ways: first, through its role as linguistic mediator, and second, as an identifying facet of cultural identity. For instance, sign language mediates experience in a unique way, as of course do all languages. The structures and vocabulary of sign language provide the framework within which experience is organised, perceived and understood, and this framework is inevitably distinct from the frameworks employed by other languages. For example, in ASL if one describes a person as VERY HARD-OF-HEARING, it means that the person has substantial residual hearing, while A LITTLE HARD-OF-HEARING would suggest far less residual hearing. In other words, the concepts themselves are based on different norms than would be the case in English (where the meanings of these two expressions, for instance, would be reversed). The use of a sign language as one's primary vernacular language is arguably the single most important element in the construction of Deaf cultural identity. Deaf cultural identity presupposes communicative competence in the community's sign language, and is impossible without it. As Schein (1984: 130) has explained, "being deaf does not in itself make one a member of the deaf community. To understand this, one has to remember that the distinguishing feature of membership in the deaf community is how one communicates". It is not merely signing that is necessary, though it is, specifically, the use of the natural sign language of the Deaf community (i.e., ASL or SASL). Many hearing people sign, but relatively few are competent in a natural sign language. For example, ASL has historically functioned as a language of group solidarity for Deaf people in the US, serving both as a badge of in-group membership and as a barrier to those outside the cultural community. Recently, as more hearing people have begun to learn ASL, new complications have arisen with respect to issues of ownership of ASL (cf. Lane et al. 1996; Levesque 2001). As one leader in the US Deaf community noted,

I have asked a number of deaf individuals how they feel about hearing people signing like a native user of ASL. The responses are mixed. Some say that it is acceptable for hearing people to use ASL like a deaf person on one condition. The condition is that this hearing person must make sure that the deaf person knows that $\mathrm{s} / \mathrm{he}$ is not deaf. Some people resent the idea of seeing hearing 
people signing like a native ASL user. Those who are resentful may feel sociolinguistic territorial invasion by those hearing people.

(Quoted in Schein and Stewart 1995: 155)

The role of sign language in the construction of Deaf identity, then, is quite complex - it is clearly a necessary condition for Deaf cultural identity, but not (as is demonstrated in the cases of hearing individuals who use a natural sign language fluently) a sufficient condition for group membership. Indeed, for non-group members, use of the natural sign language of the Deaf community can present significant challenges to one's credibility and status as a sympathetic outsider, and it is far from uncommon to find Deaf people who seek to "protectively withhold from hearing people information about the DEAF-WORLD's language and culture" (Lane et al. 1996: 71).

Members of the Deaf cultural community identify themselves as socially and culturally Deaf, maintaining a clear-cut distinction between audiological deafness and sociocultural deafness a phenomenon that is sometimes referred to as "attitudinal deafness" (cf. Reagan 1990; Janesick and Moores 1992). Thus, within an sociocultural construction of deafness, the fact of audiological deafness is actually neither a necessary nor a sufficient condition for cultural deafness. Hearing children of Deaf people (technically referred to as "CODAs", or "Children of Deaf Adults"), who grow up with a natural sign language as their first language, are (at least in some significant ways) potential members of the Deaf culture, just as older hearing people who lose their hearing are, under normal circumstances, not Deaf - they are, rather, hearing people who can no longer hear. It is interesting to note that in ASL there is actually a pejorative and insulting sign (HEAFIE) used to denigrate a deaf person who "thinks like a hearing person". Further, a common facet of cultural identity for many ethnic groups is the presence and maintenance of endogamous marital patterns, and the same is true in the case of Deaf people (cf. Reagan 1990). The high rate of in-group marriage is certainly facilitated by the role of the residential schools for the deaf, but is also tied to the common, shared language of Deaf people as well as to the power of the concept of attitudinal deafness. This concept of attitudinal deafness is, further, a key element in understanding much of Deaf humour (cf. Bienvenu 1994; Bouchauveau 1994). Jokes and funny stories abound in the DEAF-WORLD, and many involve the presumed difference between Deaf people and the DEAF-WORLD and hearing people and the hearing world - almost inevitably, as one would expect, with the punch line 
focusing on hearing people's ignorance of signing, deafness, and Deaf people. Members of the Deaf community typically have a strong sense of the history of their own community, as well as of its relationship with the broader hearing community in their own society, and this awareness has been passed from generation to generation largely through oral means in the past. Finally, there is a voluntary network of social organisations serving Deaf people, which work to maintain the cohesiveness of the Deaf community and provide, to a significant extent, for the companionship needs of group members. In the South African context, this network most notably includes DEAF-SA.

There are also differences with respect to behavioural norms between the hearing world and the DEAF-WORLD. Most notable here would be differences in eye contact patterns, rules governing the permissibility of physical contact of various sorts (including touching to gain attention), the use of facial expressions, gesturing, and so on (cf. Kersting 1997). The cultural artifacts of the Deaf community are those which are intended to emphasise membership in the Deaf culture, such as jewelry, T-shirts, bumper stickers, and so on, which often involve visual images of signs (and, most often, the I-LOVE-YOU sign). ${ }^{4}$

It is clear, then, that in a social and anthropological sense, the DEAF-WORLD can certainly be argued to be a legitimate and viable culture. Attempts to medically "cure" or "remediate" audiological deafness are thus, not surprisingly, seen by its members as not merely misguided, but also as culturally and linguistically oppressive. This point was made quite vividly by I. King Jordan, past President of Gallaudet University. Jordan was asked by the interviewer whether he wouldn't like to have his hearing restored, to which Jordan replied, "That's almost like asking a black person if he would rather be white ... I don't think of myself as missing something or as incomplete ... It's a common fallacy if you don't know deaf people or deaf issues. You think it's a limitation" (quoted in Lane 1993: 288). From within the Deaf culture, this response was appropriate, meaningful and indeed relatively uncontroversial; from outside the culture, it may be somewhat more problematic. Precisely the same situation, albeit in reverse, can be found in the following quote from a chairman of a National Institutes of Health planning group in The New York Times: "I am dedicated to curing deafness. That puts me on a collision course with those who are culturally Deaf. That is interpreted as genocide of the Deaf" (quoted in Lane et al. 1996: 379). It is the tension between the two kinds of 
constructions of deafness that is at stake here, and it is this tension that is, on a fundamental level, probably irreconcilable.

\subsection{Educational implications of cultural conceptions of deafness}

If one accepts the presence of Deaf culture, and the legitimacy of sign language, as suggested in the sociocultural paradigm, then there are a number of fairly important educational implications that one would need to address. Current models and practices in education, by and large, tend to assume and be grounded in the pathological paradigm of deafness, in which the Deaf are basically seen as deficient in significant ways when measured against a hearing norm. The acceptance of Deaf culture forces us to reconsider the "normativity of hearingness" against which the Deaf are to be measured, which in turn means that the kind of educational practice considered appropriate would look very different to much contemporary schooling. Perhaps the greatest change would be the altered status and role of sign language itself (cf. Johnson, Liddell and Erting 1989; Branson and Miller 1993). For example, a growing number of educators of the deaf have suggested that the most appropriate approach to the education of Deaf children is one that is essentially bilingual and bicultural in nature - utilising sign language and at least one spoken language, and teaching children to function in both the Deaf and hearing worlds (cf. Bouvet 1990; Gregory 1992; Nover 1995; Lane et al. 1996; Reagan 2002c, 2005a, all of whom advocate such an educational approach for deaf children).

\section{South African Sign Language}

It is well-established amongst linguists that sign languages are fully and completely human languages, meeting every reasonable criterion that we might apply to describe language (cf. Fromkin, Rodman and Hyams 2003; Valli et al. 2005). Nevertheless, the picture is considerably more complex and complicated than this might suggest. Not all signing constitutes sign language, and the diversity amongst sign languages is significant. There are, for instance, not only different natural sign languages used amongst Deaf people in other societies, but also contact sign languages commonly used by both Deaf and hearing people in their interactions, and even manual sign codes for spoken languages which are used in educational settings (cf. Bornstein 1990). For our purposes here, it is important to note that SASL is the language typically utilised in Deaf-Deaf communicative interactions in South Africa, and that it is a unique language unrelated linguistically to any of the spoken languages 
in the country.

\subsection{SASL: An overview}

The linguistic situation in South Africa is an immensely complex one, and the nature of SASL itself is both embedded in and reflective of this complexity. Although there remains much that we do not know about SASL, there is also a great deal that we do know - the result of over fifteen years of linguistic research conducted by a number of researchers who have been exploring the nature and characteristics of SASL (cf., e.g., Landman 1990; Penn 1993; Ogilvy-Foreman, Penn and Reagan 1994; Penn and Reagan 1994; Penn and Reagan 1995; Aarons 1996; Aarons and Akach 1998, 2002; Deumert 2000; Aarons and Reynolds 2003; Reagan, Penn and Ogilvy 2006). The evidence clearly and strongly supports the view that SASL is a distinct language in its own right, not a derivational, pidgin or contact language. It is a rule-governed, grammatical, systematic and non-arbitrary communication system similar in nature to other natural sign languages. The evidence for the distinctive nature of SASL provides ample documentation for the robustness of this language, which is particularly impressive given the historical oppression of Deaf people and their language in South Africa and elsewhere (cf. Penn and Reagan 1990, 1991, 1995; Penn 1992, 1993; Reagan and Penn 1997). Finally, the data appear to support the view that the primary characteristic of SASL syntax is that of spatial relationships, though clearly other significant factors play roles in morphosyntactic relationships in SASL as well (such as verbal aspect, for instance) (cf. Reagan 2007b). It is encouraging in this regard that work on SASL provides evidence and insights that can contribute to the growing body of international literature which suggests that the nature of signed language may have some universal characteristics, as well as characteristics distinct to particular individual sign languages (cf., e.g., Emmorey 2003: ix-x; Sandler and Lillo-Martin 2006: 3-18).

\subsection{Sign Language in education}

There is a substantial body of international literature devoted to making both the linguistic and the educational case for the use of sign language in the education of Deaf children. The arguments in favour of the use of sign language are strong ones, and include empirical evidence related to the relative ease of acquisition of sign language for Deaf children. Such acquisition of a natural sign language by deaf children is in marked contrast to the acquisition of either a spoken language or a manual code for a spoken language for such children. Indeed, 
acquisition of sign language by children (deaf or hearing, in fact) parallels the normal first language acquisition process documented for hearing children. In addition, sign language can be used effectively to teach both academic content and literacy skills in the spoken language, and finally, for deaf children as for all children, early language acquisition is essential "for the continual development of cognitive skills and later acquisition of literacy skills in either a first or second language" (Paul no date: 2). Underlying such arguments is a generally unarticulated view of sign language as the "natural" language of the Deaf child. There is, to be sure, something of a "sleight of hand" argument here, since what most advocates of the use of sign language in deaf education really want to argue is that the use of sign language is a matter of using the child's mother tongue (cf. Bergmann 1994). In the case of the vast majority of Deaf children (who have hearing, and thus, generally non-signing, parents), sign language is not in fact, at least in a technical sense, the child's mother tongue - indeed, the question of what the mother tongue of the prelingually Deaf child is, is a particularly vexing and complex one. Nevertheless, while the question of what the real mother tongue of the Deaf child actually may be remains unresolved in an important sense, what is quite clear is that of the available options, simply from a practical and pragmatic perspective, education in sign language does, in the view of the majority of educators of the deaf, constitute the most reasonable choice at this time.

While the use of sign language in the education of Deaf children may well make sense both educationally and linguistically, this does not mean that it is common, let alone universal, practice. For the most part, sign languages are still rarely used in formal educational settings; rather, where signing is employed, either a form of contact sign language or an artificially constructed manual sign codes for a spoken language is most likely to be utilised. In an educational environment based on a cultural model of Deafness, as articulated by Johnson et al. (1989) at Gallaudet University, instruction would take place through the medium of the appropriate natural sign language, and the goal for all students would be functional bilingualism in the natural sign language and the dominant spoken language of the society. Students would study not only the common curriculum shared with their hearing peers, but would also study the history of the Deaf culture and Deaf communities in other parts of the world. Thus, the goal of such a programme would be students who would truly be both bilingual and bicultural, able to function competently and comfortably in the hearing world, while still at home in the DEAF-WORLD. Such a programme, of course, would almost certainly 
entail Deaf students studying together, in a setting not unlike that provided by residential schools, rather than in mainstreamed settings. This is an important point, since at the present time mainstreaming is almost universally seen as a "good thing" in educational circles: its intent, after all, is to open up schools to children with disabilities and to provide a more appropriate and fulfilling education for all students, both the "abled" and the "disabled", and to end the past practices of inappropriately segregating students with disabilities. In other words, mainstreaming, or "inclusive education" as it is also called, is intended to both empower students with disabilities and to expose and sensitise other students to disabilities. These are certainly both admirable goals, but the problem for Deaf students is that mainstreaming almost inevitably means a lack of significant contact with other Deaf people, given the relatively small numbers of Deaf students in any particular geographic setting. Instead of thinking about appropriate educational placement being based on the "least restrictive environment", to use the popular educational phrase, we might be better off (at least in the case of the Deaf) favouring the "most enabling environment" - a subtle distinction, but nevertheless an important one. It is important to note, though, that this does not automatically rule out the inclusion of hearing students in such an educational setting. Such students would be welcome, but only with the clear understanding that such a project rests on the rejection of the dominance of hearing cultural, behavioural and linguistic norms. Further, an educational programme grounded in a cultural model of Deafness would actively encourage Deaf children to be exposed to a wide variety of Deaf adults. In fact, given the importance attached to the use of sign language and familiarity with the Deaf culture, such an educational programme would generally favour the use of Deaf teachers - a radical departure from current educational practice in most settings. Finally, control of the educational programme would rest, to a significant extent, in the hands of the Deaf community (locally and, in the South African case, nationally), rather than in the hands of hearing experts on deafness and deaf education, as is typically the case at present (cf. Lane et al. 1996: 213-265).

\subsection{Language rights in Deaf education}

The use of sign language in the education of Deaf children is not merely good educational and linguistic practice, however; it is also arguably the only viable outcome from a consideration of issues of language and the Deaf. Issues of language rights, as a core part of the more general concern with both human rights and language policy, have been gaining increasing attention from both linguists and policy-makers in recent years. (Amongst the major figures to 
have written in favour of language rights in the educational context are Skutnabb-Kangas and Phillipson 1995; Kontra, Phillipson, Skutnabb-Kangas and Várady 1999; Phillipson 2000; Skutnabb-Kangas 2000a, 2000b; May 2005.) The case of the language rights of sign language users is an area that has received noteworthy attention in this regard. Minority language rights, both because they have implications for resource allocation and because they touch on important issues of national and ethnic identity, are often a controversial matter, in spite of public proclamations to the contrary, and the question of minority language rights for the Deaf is an especially complex and difficult one - not only because of issues of language rights per se, it should be noted, but rather, because the vast majority of Deaf people have hearing parents. Nevertheless, there is powerful and compelling literature dealing explicitly with the language rights of the Deaf, and this is literature that is certainly worth noting given our concerns here (cf., e.g., Skutnabb-Kangas 1994; Muzsnai 1999; Jokinen 2000; Reagan 2005b). In essence, what this suggests is that the language of instruction for Deaf children is not only a linguistic and pedagogical matter (although these are obviously the most important aspects of the argument), but is also a matter of human rights.

\subsection{SASL and the education of the Deaf}

It is interesting to note that SASL has to some extent been recognised constitutionally and legally in ways that would appear to indicate cognisance of the language rights of the Deaf in South Africa, although it is also important to note that such rights are all too often not yet manifested in practice (cf. Reagan, Penn and Ogilvy 2006; Reagan 2007c). The Constitution of the Republic of South Africa (Republic of South Africa 1996a) identifies a total of eleven official languages: Afrikaans, English, isiNdebele, Sepedi, Sesotho, Setswana, SiSwati, Tshivenda, Xitsonga, isiXhosa, and isiZulu. Although SASL is not amongst the eleven official languages, it is nevertheless directly mentioned in the Constitution. In Chapter 1 (6: 5), the Constitution created the Pan South African Language Board (PanSALB), which is empowered to "promote, and create conditions for, the development and use of (i) all official languages; (ii) the Khoi, Nama and San languages; and (iii) sign language" (cf. also the Pan South African Language Board Act (Republic of South Africa 1995)). Under the auspices of PanSALB, a specific National Language Board has been created for each of the official languages as well as for the Khoe and San languages (PanSALB 2005: 15). In 2001, a National Language Board was created for SASL as well, with two specific objectives, namely (i) initiating and implementing strategic projects aimed at creating awareness, identifying 
needs and promoting SASL; and (ii) identifying and funding projects aimed at developing SASL (PanSALB 2005: 15). The National Language Policy Framework, issued by the Department of Arts and Culture (Republic of South Africa 2002), similarly includes mention of SASL. In the educational sphere, the South African Schools Act (Republic of South Africa 1996b) also includes specific mention of SASL in the section devoted to language policy in government schools. Chapter 2 (29: 2) of the Constitution (the "Bill of Rights") guarantees that "(e)veryone has the right to receive education in the official language or languages of their choice in public educational institutions where that education is reasonably practicable" The South African Schools Act takes this right further, noting that "a recognised Sign Language has the status of an official language for purposes of learning at a public school" (Chapter 2 (6: 4)). This point is further elucidated and reinforced in the Language in Education Policy of the Department of Education (Republic of South Africa 1997), which is remarkably sympathetic to issues of the Deaf community in South Africa and to SASL. The Language in Education Policy (Republic of South Africa 1997) begins with a "Preamble" which is intended to set the stage for the national approach to educational language policy:

This Language-in-Education Policy Document should be seen as part of a continuous process by which policy for language in education is being developed as part of a national language plan encompassing all sectors of society, including the deaf community ... In terms of the new Constitution of the Republic of South Africa, the government ... recognises that our cultural diversity is a valuable national asset and hence is tasked ... to promote multilingualism, the development of the official languages, and respect for all languages used in the country, including South African Sign Language ...

(Republic of South Africa 1997, my emphasis)

In other words, at least at a rhetorical level, the rights of the deaf community, especially with respect to SASL, are both constitutionally and legally protected in the South African context. Although not an official language of the Republic, SASL would appear to have virtually the same rights as an official language.

\subsection{Teaching SASL to the hearing}

Up to this point, we have been concerned with sign language as the medium of instruction in 
the education of Deaf children, and while this is of considerable importance, it is not the sole area in which sign language in education policy has proven to be somewhat controversial elsewhere in the world. There is also the matter of the teaching and learning of a particular sign language as a foreign or additional language by hearing individuals (cf. Wilcox 1988; Belka 2000). The development of courses, programmes, textbooks and other curricular materials designed to teach sign language to hearing people has, perhaps somewhat surprisingly, met with a certain amount of resistance amongst some educationists and policymakers. In the US, Wilcox and Wilcox (1997: 50) have reported an increase in enrolment in ASL courses at the post-secondary level of $181 \%$ over a five-year period, and a number of US state legislatures have passed legislation explicitly recognising ASL as a distinct language in its own right, thus allowing for schools to teach ASL as a foreign language. At the same time, there has been a powerful backlash to such developments, seen most clearly in the resistance amongst many educationists (and especially many foreign language teachers) to the inclusion of ASL as a foreign language option in secondary schools and universities. Such objections, although not uncommon, have been widely rejected by policy-makers and linguists, and programmes offering ASL for hearing individuals in the US continue to grow (cf. Wilcox and Wilcox 1997; Reagan 2002b). Although the specifics of such programmes vary significantly, as one would expect, it is important to note that at least at the tertiary level many of the instructors of ASL in the US are themselves Deaf (cf. Reagan 2000).

In South Africa, growth in numbers of students, especially at the tertiary level, who are studying SASL parallels such developments. Amongst the tertiary institutions currently offering SASL in South Africa are the University of the Witwatersrand and the University of the Free State, and it is likely that additional programmes will be developed in the near future.

\section{Recommendations for language-in-education policy in South Africa}

The status of SASL as a minority language, and of the Deaf as a cultural minority group, in many ways parallels the situation of many other languages and cultural groups in South Africa (cf. Reagan 2007a). Debates about the constitutional status of SASL, as well as about its use in educational settings, have not only reflected the social and political forces affecting language and language policy, but have also mirrored ongoing discussions in the country about human rights, economic and social justice, education, and a host of other issues. In this 
section of the paper, I will explore some of the implications of the knowledge base related to sign language explicated above for language-in-education policy in contemporary South Africa.

There are in fact two distinct, albeit related, ways in which the implications of the knowledge base related to sign language, broadly conceived, can be elaborated. First, there are the implications of the knowledge base for the general philosophical and conceptual framework in which discussions about education and language policy take place and are made, not only in South Africa but also elsewhere. Second, there are specific, context-bound recommendations related to the particular case of South Africa that emerge from the knowledge base. Each of these sets of implications will be briefly explored below.

\subsection{General implications of the sociocultural view of Deafness for language-in- education policy}

Amongst the general philosophical and conceptual implications that can be derived from the discussion presented thus far are three broad sets of concerns: (i) the legitimacy of sign language and Deaf culture, (ii) the need for a re-evaluation of the deficit or pathological model in addressing the linguistic, cultural and educational issues related to the Deaf, and (iii) the importance of recognising and utilising empowerment perspectives in such matters. In terms of the legitimacy of sign language and Deaf culture, although it unquestionably remains something of an on-going challenge to convince parts of the general public that sign languages are "real" languages, and that Deaf culture is both real and vibrant, the evidence for both claims is overwhelming and this is true both internationally and in the South African context.

Related to this challenge is another barrier to the development of appropriate responses to deafness and the use of sign language: the fairly common assumption by well-intentioned individuals that deafness is a tragedy for the individual - a tragedy that we should do everything in our power to help overcome. This deficit and pathological view of deafness inevitably leads to paternalism, and in turn to the imposition of hearing-oriented social, political, and educational agendas on the Deaf (cf. Branson and Miller 1993: 21-41, 2002: 233-253; Reagan 2002c: 41-66; Ladd 2003: 434-461). As Hahn (1986) has argued with respect to paternalism toward disabled people in general, 
(p)aternalism enables the dominant elements of a society to express profound and sincere sympathy for the members of a minority group while, at the same time, keeping them in a position of social and economic subordination. It has allowed the nondisabled to act as the protectors, guides, leaders, role-models, and intermediaries for disabled individuals who, like children, are often assumed to be helpless, dependent, asexual, economically unproductive, physically limited, emotionally immature, and acceptable only when they are unobtrusive ...

(Hahn 1986: 130)

Such paternalistic approaches to those with perceived disabilities perhaps inevitably leads to the infantilisation of such individuals, and essentially constitutes disempowerment. This analysis of paternalism toward the disabled is especially powerful and vivid in the case of the Deaf, as Lane (1992) has noted:

Like the paternalism of the colonisers, hearing paternalism begins with defective perception, because it superimposes its image of the familiar world of hearing people on the unfamiliar world of deaf people. Hearing paternalism likewise sees its task as 'civilising' its charges: restoring deaf people to society. And hearing paternalism fails to understand the structure and values of deaf society. The hearing people who control the affairs of deaf children and adults commonly do not know deaf people and do not want to. Since they cannot see deaf people as they really are, they make up imaginary deaf people of their own, in accord with their own experiences and needs.

(Lane 1992: 37)

In both the cases of the legitimacy of sign language and Deaf culture and that of hearing paternalism toward the DEAF-WORLD, comparable attitudes and beliefs, if directed to any other cultural and linguistic community, would be dismissed out-of-hand, and labelling them as "ablest" would certainly not be seen as unreasonable (cf. Phillipson 1988). Finally, an important development in the DEAF-WORLD internationally in recent years has been the growing demand by Deaf people (and, indeed, of other so-called "disabled" groups) for control of their own destiny (cf. Davis 1995, 1997). As one well-known disabilities studies 
scholar has proclaimed, "Nothing about us without us" (Charlton 1998).

\subsection{Implications and recommendations of the sociocultural view of Deafness for language-in-education policy in the South African context}

Context-specific implications and recommendations for the South African setting that emerge from the arguments presented here include a number of significant suggestions related to both educational practice and language policy issues more generally. Specific recommendations include:

- $\quad$ SASL should be utilised as a recognised medium of instruction in deaf education. In many instances, this will be ensuring that students have a solid foundation in SASL. It also means that all teachers of the Deaf should be required to demonstrate communicative competence in SASL. Further, it is also obviously desirable that Deaf individuals be recruited for teaching positions in deaf education, as well as in other educational settings, and appropriate action should be taken to encourage such efforts.

- There should be provision for the teaching of SASL for hearing groups and individuals. Special provisions should be made for hearing parents of Deaf children, as well as for future teachers of the Deaf and for other professionals likely to come into contact with the Deaf. Furthermore, SASL should be offered as a second/additional language option for students in both government school and university settings.

- $\quad$ SASL should be added as one of the official languages of South Africa, and should be accorded the same status as any other official language.

- Language planning and policy efforts targeted on SASL by the Pan South African Language Board and other appropriate governmental agencies should be increased, and support should be provided especially for the teaching and learning of SASL and for its use in public settings (including in the media).

It is important to note here that none of these recommendations is in any way intended to suggest that it is not also essential for Deaf students to learn to read and write spoken 
languages, and to function, to the best of their abilities, in the dominant hearing society. The need for the Deaf to live and thrive in what is inevitably a multilingual environment is beyond question, as indeed it should be for all South Africans.

\section{Conclusion}

The purpose of this article has been to attempt to present an overview of the complex issues presented by the case of SASL for language-in-education policy, and to offer a series of recommendations for how these issues might best be addressed. In order to accomplish this, I have drawn on both the growing research literature in South Africa and the extensive international research that deals with issues of sign language and the DEAF-WORLD, especially in educational settings. Ultimately, the issues that emerge in a serious consideration of the most appropriate social and educational challenges presented by sign language and the culture of the DEAF-WORLD are ethical ones, concerned with matters of social justice. As Archbishop Desmond Tutu (1983: 45) once observed about oppression in South Africa under the apartheid regime, "at present nobody is really free; nobody will be really free until Blacks are free. Freedom is indivisible." The same is true with regard to the rights of all dominated cultural and linguistic groups, and it certainly applies to the case of the Deaf.

\section{Notes}

1. The history of language planning and language policy in South Africa is an important and fascinating case study of language policy studies more generally. It is obviously neither possible nor appropriate to provide an inclusive list of recent works dealing with this topic, but amongst those which provide good overviews are Reagan (2001, 2002a), Hill and Van Zil (2002), Murray (2002), Webb (2002, 2004, 2006a, 2006b), Alexander (2004), Kamwangamalu (2004), Ridge (2004), Wright (2004), Du Plessis (2006), McLaughlin (2006).

2. I have followed the common practice of indicating a particular sign by writing its English meaning in capital letters (e.g., BOY). It should be noted that many signs require multiple English words to represent a single sign; in these instances, the English words are joined by hyphens to indicate that although there are several English words used to express the meaning of the sign, there is only a single sign (e.g., DEAF-WORLD). 
3. Much of this section is based on the relevant literature on the nature of the DEAFWORLD in the US. There is comparable literature on Britain, and a growing body of literature dealing with the DEAF-WORLD elsewhere. Although only limited research has been conducted in South Africa, anecdotal and experiential evidence indicates strongly that the same issues and characteristics apply here as elsewhere in general terms.

4. The over-use of the I-LOVE-YOU sign has even generalised a degree of hostility amongst some in the DEAF-WORLD, as Tom Willard (1993) articulated in a short essay entitled I've had enough of the I-LOVE-YOU sign, thanks.

\section{References}

Aarons, D. 1996. Signed languages and professional responsibility. Stellenbosch Papers in Linguistics 29: 285-311.

Aarons, D. and P. Akach. 1998. South African Sign Language - One language or many? A sociolinguistic question. Stellenbosch Papers in Linguistics 31: 1-28.

Aarons, D. and P. Akach. 2002. South African Sign Language: One language or many? In R. Mesthrie (ed). Language in South Africa. Cambridge: Cambridge University Press. pp. 127-147.

Aarons, D. and L. Reynolds. 2003. South African Sign Language: Changing policies and practice. In L. Monaghan, C. Schmaling, K. Nakamura and G. Turner (eds). Many ways to be deaf: International variation in deaf communities. Washington, DC: Gallaudet University Press. pp. 194-210.

Alexander, N. 2004. The politics of language planning in post-apartheid South Africa. Language Problems and Language Planning 28: 113-130.

Baker, C. 1999. Sign language and the deaf community. In J. Fishman (ed). Handbook of language and ethnic identity. New York: Oxford University Press. pp. 122-139.

Belka, R. 2000. Is American Sign Language a 'foreign' language? Northeast Conference on the Teaching of Foreign Languages Review 48: 45-52.

Bergmann, R. 1994. Teaching sign language as the mother tongue in the education of deaf children in Denmark. In I. Ahlgren and K. Hyltenstam (eds). Bilingualism in deaf education. Hamburg: Signum Press. pp. 83-90.

Bienvenu, M. 1994. Reflections of deaf culture in deaf humor. In C. Erting, R. Johnson, D. Smith and B. Snider (eds). The deaf way: Perspectives from the international conference on deaf culture. Washington: Gallaudet University Press. pp. 16-23. 
Bornstein, H. (ed). 1990. Manual communication: Implications for education. Washington: Gallaudet University Press.

Bouchauveau, G. 1994. Deaf humor and culture. In C. Erting, R. Johnson, D. Smith and B. Snider (eds). The deaf way: Perspectives from the international conference on deaf culture. Washington: Gallaudet University Press. pp. 24-30.

Bouvet, D. 1990. The path to language: Bilingual education for deaf children. Clevedon: Multilingual Matters.

Bragg, L. (ed.) 2001. DEAF WORLD: A historical reader and primary sourcebook. New York: New York University Press.

Branson, J. and D. Miller. 1993. Sign language, the deaf and the epistemic violence of mainstreaming. Language and Education 7: 21-41.

Branson, J. and D. Miller. 2002. Damned for their difference: The cultural construction of deaf people as disabled. Washington: Gallaudet University Press.

Charlton, J. 1998. Nothing about us without us: Disability oppression and empowerment. Berkeley: University of California Press.

Chisanga, T. and N. Kamwangamalu. 1997. Owning the other tongue: The English language in Southern Africa. Journal of Multilingual and Multicultural Development 18: 89-99.

Davis, L. 1995. Enforcing normalcy: Disability, deafness, and the body. London: Verso.

Davis, L. (ed). 1997. The disability studies reader. New York: Routledge.

De Kadt, E. 1996. Language and apartheid: The power of minorities. Alternation 3: 184-194.

De Kadt, J. 2006. Language development in South Africa: Past and present. In V. Webb and T. du Plessis (eds). The politics of language in South Africa. Pretoria: Van Schaik. pp. 40-56.

Deumert, A. 2000. The sociolinguistics of sign language. In R. Mesthrie, J. Swann, A. Deumert and W. Leap (eds). Introducing sociolinguistics. Edinburgh: Edinburgh University Press. pp. 419-448.

Dolnick, E. 1993. Deafness as culture. The Atlantic 272: 37-53.

Du Plessis, T. 2006. Mismatch or misfit? Critical perspectives on language policy development in South Africa. In C. van der Walt (ed). Living through languages: An African tribute to René Dirven. Stellenbosch: SUN Press. pp. 37-53.

Emmorey, K. (ed.) 2003. Perspectives on classifier constructions in sign languages. Mahwah: Lawrence Erlbaum.

Fromkin, V., R. Rodman and N. Hyams. 2003. An introduction to language. $7^{\text {th }}$ edition. 
Boston: Thomson/Heine.

Gregory, S. 1992. The language and culture of deaf people: Implications for education. Language and Education 6: 183-197.

Hagemeyer, A. 1992. The red notebook. Silver Spring: National Association of the Deaf.

Hahn, H. 1986. Public support for rehabilitation programs: The analysis of U.S. disability policy. Disability, Handicap and Society 1: 121-137.

Heugh, K. 1995. Disabling and enabling: Implications of language policy trends in South Africa. In R. Mesthrie (ed). Language and Social History. Cape Town: David Philip. pp. 329-350.

Heugh, K. 2002. Recovering multilingualism: Recent language policy developments. In R. Mesthrie (ed). Language in South Africa. Cambridge: Cambridge University Press. pp. 449-475.

Hill, P. and S. van Zil. 2002. English and multilingualism in the South African engineering workplace. World Englishes 21: 23-35.

Janesick, V. and D. Moores. 1992. Ethnic and cultural considerations. In T. Kluwin, D. Moores and M. Gaustad (eds). Toward effective public school programs for deaf students: Context, process, and outcomes. New York: Teachers College Press. pp. 4965.

Johnson, R., S. Liddell and C. Erting. 1989. Unlocking the curriculum: Principles for achieving access in deaf education. Gallaudet University Research Institute Working Paper 89/3.

Jokinen, M. 2000. The linguistic human rights of sign language users. In R. Phillipson (ed). Rights to language: Equity, power, and education. Mahwah: Lawrence Erlbaum. pp. 203-213.

Kamwangamalu, N. 1997. Multilingualism and education policy in post-apartheid South Africa. Language Problems and Language Planning 21: 234-253.

Kamwangamalu, N. 2004. The language policy/language economics interface and mother-tongue education in post-apartheid South Africa. Language Problems and Language Planning 28: 131-146.

Kersting, S. 1997. Balancing between deaf and hearing worlds: Reflections of mainstreamed college students on relationships and social interactions. Journal of Deaf Studies and Deaf Education 2: 252-263.

Kontra, M., R. Phillipson, T. Skutnabb-Kangas, and T. Várady (eds). 1999. Language: A right 
and a resource. Budapest: Central European University Press.

Kuhn, T. 1996. The structure of scientific revolutions. $3^{\text {rd }}$ edition. Chicago: University of Chicago Press.

Ladd, P. 2003. Understanding deaf culture: In search of deafhood. Clevedon: Multilingual Matters.

Landman, K. 1990. Taalonderwys en die dowe kind. Journal for Language Teaching 24: 4253.

Lane, H. 1992. The mask of benevolence: Disabling the deaf community. New York: Alfred A. Knopf.

Lane, H. 1993. Cochlear implants: Their cultural and historical meaning. In J. van Cleve (ed.) Deaf history unveiled. Washington: Gallaudet University Press.

Lane, H., R. Hoffmeister and B. Bahan. 1996. A journey into the DEAF WORLD. San Diego: DawnSign Press.

Levesque, J. 2001. Let's return ASL to deaf ownership. In L. Bragg (ed.) DEAF WORLD: A historical reader and primary sourcebook. New York: New York University Press. pp. 116-117.

May, S. 2005. Language rights: Moving the debate forward. Journal of Sociolinguistics 9: 319-347.

McLaughlin, E. 2006. Language, democracy and governance in South Africa. In V. Webb and T. du Plessis (eds). The politics of language in South Africa. Pretoria: Van Schaik.

Murray, S. 2002. Language issues in South African education: An overview. In R. Mesthrie (ed). Language in South Africa. Cambridge: Cambridge University Press. pp. 434-448.

Muzsnai, I. 1999. The recognition of sign language: A threat or the way to a solution? In M. Kontra, R. Phillipson, T. Skutnabb-Kangas and T. Várady (eds.) Language: A right and a resource - Approaching linguistic human rights. Budapest: Central European University Press. pp. 279-296.

Nover, S. 1995. Politics and language: American Sign Language and English in deaf education. In C. Lucas (ed). Sociolinguistics in deaf communities. Washington: Gallaudet University Press.

Ogilvy-Foreman, D., C. Penn and T. Reagan. 1994. Selected syntactic features of South African Sign Language: A preliminary analysis. South African Journal of Linguistics 12: $118-123$.

Padden, C. and T. Humphries. 2005. Inside deaf culture. Cambridge, MA: Harvard University 
Press.

Pan South African Language Board. 2005. Annual report: 2004/2005. Pretoria: Author.

Patton, M. 1978. Utilisation-focused evaluation. Beverly Hills: Sage.

Paul, P. No date. ASL to English: A bilingual minority-language immersion program for deaf students. Unpublished manuscript.

Penn, C. 1992. The sociolinguistics of South African Sign Language. In R. Herbert (ed). Language and society in South Africa. Johannesburg: University of the Witwatersrand Press. pp. 277-284.

Penn, C. 1993. Signs of the times: Deaf language and culture in South Africa. South African Journal of Communication Disorders 40: 11-23.

Penn, C. and T. Reagan. 1990. How do you sign 'apartheid'? The politics of South African Sign Language. Language Problems and Language Planning 14: 91-103.

Penn, C. and T. Reagan. 1991. Toward a national policy for deaf education in the 'new' South Africa. South African Journal of Communication Disorders 38: 19-24.

Penn, C. and T. Reagan. 1994. The properties of South African Sign Language: Lexical diversity and syntactic unity. Sign Language Studies 85: 319-327.

Penn, C. and T. Reagan. 1995. On the other hand: Implications of the study of South African Sign Language for the education of the deaf in South Africa. South African Journal of Education 15: 92-96.

Phillipson, R. 1988. Linguicism: Structures and ideologies in linguistic imperialism. In T. Skutnabb-Kangas and J. Cummins (eds). Minority education: From shame to struggle. Clevedon: Multilingual Matters. pp. 339-358.

Phillipson, R. (ed). 2000. Rights to language: Equity, power and education. Mahwah: Lawrence Erlbaum.

Reagan, T. 1990. Cultural considerations in the education of the deaf. In D. Moores and K. Meadow-Orlans (eds). Educational and developmental aspects of deafness. Washington: Gallaudet University Press.

Reagan, T. 1995. A sociocultural understanding of deafness: American Sign Language and the culture of deaf people. International Journal of Intercultural Relations 19: 239251.

Reagan, T. 2000. But does it count? Reflections on "signing" as a foreign language. Northeast Conference on the Teaching of Foreign Languages Review 48: 16-26.

Reagan, T. 2001. The promotion of linguistic diversity in multilingual settings: Policy and 
reality in post-apartheid South Africa. Language Problems and Language Planning 25: $51-72$.

Reagan, T. 2002a. Language planning and language policy: Past, present and future. In R. Mesthrie (ed). Language in South Africa. Cambridge: Cambridge University Press. pp. 419-433.

Reagan, T. 2002b. Teaching and learning sign language as a 'foreign' language. Journal of Language Teaching 36: 175-205.

Reagan, T. 2002c. Toward an 'archeology of deafness': Etic and emic constructions of identity in conflict. Journal of Language, Identity and Education 1: 41-66.

Reagan, T. 2005a. A case study in cultural and linguistic difference: The DEAF WORLD. In T. Osborn (ed). Language and cultural diversity in the United States. Westport: Praeger Press. pp. 53-64.

Reagan, T. 2005b. Language policy and sign languages. In T. Ricento (ed). An introduction to language policy: Theories and methods. Oxford: Blackwell.

Reagan, T. 2007a. Language-in-education policy in South Africa: The challenge of sign language. Africa Education Review 4: 26-41.

Reagan, T. 2007b. The times of our signs: Aspect and aspectual markers in American Sign Language. Southern African Linguistics and Applied Language Studies 25: 17-26.

Reagan, T. 2007c. Multilingualism and exclusion: American Sign Language and South African Sign Language. In P. Cuvelier, T. du Plessis, M. Meeuwis and L. Teck (eds). Multilingualism and exclusions: Policy, practice and prospects. Pretoria: Van Schaik. pp. 162-173.

Reagan, T. and C. Penn. 1997. Language policy, South African Sign Language, and the deaf: Social and educational implications. Southern African Journal of Applied Language Studies 5: 1-13.

Reagan, T., C. Penn and D. Ogilvy. 2006. From policy to practice: Sign language developments in post-apartheid South Africa. Language Policy 5: 187-208.

Republic of South Africa. 1995. Pan South African Language Board Act (No. 59). Pretoria: Author.

Republic of South Africa. 1996a. Constitution of the Republic of South Africa. Pretoria: Author.

Republic of South Africa. 1996b. South African Schools Act (No. 84). Pretoria: Author.

Republic of South Africa. 1997. Language in education policy (Department of Education, 14 
July). Pretoria: Author.

Republic of South Africa. 2002. National language policy framework (Department of Arts and Culture, 13 November). Pretoria: Author.

Ridge, S. 1996. Language policy in a democratic South Africa. In M. Herrman and B. Burnaby (eds). Language policies in English-dominant countries. Clevedon: Multilingual Matters. pp. 15-34.

Ridge, S. 2004. Language planning in a rapidly changing multilingual society: The case of English in South Africa. Language Problems and Language Planning 28: 199-215.

Sandler, W. and D. Lillo-Martin. 2006. Sign language and linguistic universals. Cambridge: Cambridge University Press.

Schein, J. 1984. Speaking the language of sign: The art and science of signing. Garden City: Doubleday.

Schein, J. and D. Stewart. 1995. Language in motion: Exploring the nature of sign. Washington: Gallaudet University Press.

Skutnabb-Kangas, T. 1994. Linguistic human rights: A prerequisite for bilingualism. In I. Ahlgren and K. Hyltenstam (eds). Bilingualism in deaf education. Hamburg: Signum Press. pp. 139-159.

Skutnabb-Kangas, T. 2000a. Linguistic genocide in education or worldwide diversity and human rights? Mahwah: Lawrence Erlbaum.

Skutnabb-Kangas, T. 2000b. Linguistic human rights and teachers of English. In J. Hall and W. Eggington (eds). The sociopolitics of English language teaching. Clevedon: Multilingual Matters. pp. 22-44.

Tutu, D. 1983. Hope and suffering. Grand Rapids: William Eerdamans.

Valli, C., C. Lucas and K. Mulrooney. 2005. Linguistics of American Sign Language: An introduction. $4^{\text {th }}$ edition. Washington: Gallaudet University Press.

Verhoef, M. 1998. 'n Teoretiese aanloop tot taalgesindheidsbeplanning in Suid-Afrika. South African Journal of Linguistics 16: 27-33.

Webb, V. 2002. Language in South Africa: The role of language in national transformation, reconstruction and development. Amsterdam: John Benjamins.

Webb, V. 2004. African languages as media of instruction in South Africa: Stating the case. Language Problems and Language Planning 28: 147-173.

Webb, V. 2006a. On a normative approach to language planning in South Africa. In V. Webb and T. du Plessis (eds). The politics of language in South Africa. Pretoria: Van Schaik. 
190 Timothy Reagan

pp. 147-163.

Webb, V. 2006b. The non-use of African languages in education in Africa. In C. van der Walt (ed). Living through languages: An African tribute to René Dirven. Stellenbosch: SUN Press. pp. 131-145.

Wilcox, S. (ed). 1988. Academic acceptance of American Sign Language Special issue of Sign Language Studies 59.

Wilcox, S. and P. Wilcox. 1997. Learning to see: American Sign Language as a second language. $2^{\text {nd }}$ edition. Washington: Gallaudet University Press.

Willard, T. 1993. I've had enough of the I-LOVE-YOU sign, thanks. Silent News 25: 2.

Wright, L. 2004. Language and value: Towards accepting a richer linguistic ecology for South Africa. Language Problems and Language Planning 28: 175-197. 